\title{
Synthesis, characterization and photovoltaic performance of novel glass-forming perylenediimide derivatives
}

\author{
Tham Adhikari, ${ }^{\mathrm{a}}$ Zahra Ghoshouni Rahami, ${ }^{\mathrm{b}}$ Jean-Michel Nunzi, ${ }^{\mathrm{c*}}$ and Olivier Lebel ${ }^{\mathrm{b} *}$ \\ ${ }^{a}$ Department of Chemistry, Queen's University, Kingston, K7L 3N6, Canada. \\ b Department of Chemistry and Chemical Engineering, Royal Military College of Canada, Kingston, ON, K7K 7B4, Canada. \\ c Department of Chemistry, Department of Physics, Engineering Physics and Astronomy, Queen's University, Kingston, K7L 3N6, \\ Canada.
}

*Corresponding Author. E-mail address: nunzijm@queensu.ca (J.-M. Nunzi); Olivier.Lebel@rmc.ca (O. Lebel).

\begin{abstract}
Novel glass-forming perylene-3,4,9,10-tetracarboxylic diimide (PDI) derivatives were synthesized from 1,7-dibromoperylene-3,4,9,10tetracarboxylic diimides by nucleophilic substitution with a glass-forming mexylaminotriazine unit, characterized, and their performance as electron acceptors in bulk heterojunction photovoltaic cells with P3HT as donor were studied. Imide groups (octyl and 2,6diisopropylphenyl) and bay substituents (bromo or pyrrolidinyl) were used to study the impact of sterics and electronics on device performance. The HOMO and LUMO levels of the materials were determined using cyclic voltammetry. The morphology and packing behaviour of molecules in films of blends with P3HT were studied using Atomic Force Microscopy and X-ray diffraction, and in all four cases, the PDI derivatives remain in the amorphous phase, while the P3HT portion of the blends crystallizes. The devices gave photovoltaic performances ranging from 0.2 to $0.6 \%$, and while the bay substituents showed negligible impact on device performance, switching from bulky 2,6-diisopropylphenyl imide groups to linear octyl chains improved the efficiency of the devices by $36 \%$, current density by $66 \%$ and fill factor by $16 \%$. The performances observed for devices incorporating these PDI glasses are comparable to that of devices with crystalline PDI acceptors.
\end{abstract}

Keywords: photovoltaic cells, bulk heterojunction, molecular glass, fullerene-free acceptor, perylenediimide, aggregation

\section{Introduction}

Due to the availability of carbon feedstocks and flexible organic synthetic methodologies, organic materials have become extremely attractive for photovoltaic applications. ${ }^{1-3}$ Depending on the solubility of organic materials, organic PV cells can be fabricated either by vacuum or by printing technologies such as spin-coating, drop-casting, doctor blading, inkjet printing, screen printing and roll-to-roll printing. Tang et al reported in 1986 a p-n heterojunction device with a power conversion efficiency of $1 \%$ using copper phthalocyanine and a perylene-3,4,9,10-tetracarboxylbis-benzimidazole (PTCBI) electron donor and acceptor, respectively. ${ }^{4}$ In recent years, great progress has been achieved in the development of solution-processed bulk heterojunction PV cells, and the technology has reached the early stages of commercialization. Currently, organic PV cells have been demonstrated to exhibit power conversion efficiency above $9 \% .^{5,6}$ The high efficiency of bulk heterojunctions is due to exciton dissociation at the interface between the electron donor and acceptor materials in the intimately mixed system and followed by efficient charge separation and transport to the electrodes by diffusion of charges in the interpenetrating donor and acceptor network, thereby facilitating an efficient charge separation due to large interfacial area. ${ }^{7-10}$ So far, various organic materials have been developed as electron donor or p-type materials, which have improved properties such as high absorption, hole mobility, and adequately tuned HOMO and LUMO levels. ${ }^{11-13}$ However, the development of electron acceptors or n-type materials is far behind that of donor materials. The dominant acceptors in bulk heterojunction PV cells are fullerene derivatives due to their high electron mobility, large electron affinity, and capacity to pack efficiently to form a percolated tridimensional supramolecular network. However, fullerenes absorb light only weakly in the visible region and play only a limited role in the light harvesting process. In addition, their high synthesis costs and limited tunability of energy levels hinder the commercial success of fullerene-based organic PV cells., ${ }^{9,10,14}$ As the development of optimal electron acceptor materials is equally important to that of donor materials for the improvement of device performances, it is crucial to develop optimal non-fullerene acceptors for organic PV cells with improved performances. ${ }^{15,16}$

3,4,9,10-Perylenetetracarboxylic diimide (PDI) derivatives are promising candidates as acceptors in organic photovoltaics. Not only do PDI derivatives display high electron mobilities, ${ }^{17}$ but they also possess high molar absorption coefficients in the visible range. ${ }^{18}$ Moreover, they can be synthesized in large scale in relatively economic fashion. ${ }^{10}$ The LUMO of parent 3,4,9,0perylenetetracarboxylic diimide is similar to that of PCBM. ${ }^{19}$ 
Their optoelectronic properties can be easily tuned by tailoring the substituents on the imide groups or on the bay positions. ${ }^{14,20-22}$ In addition, the low-lying HOMO levels of PDI derivatives can facilitate the hole transfer process from the PDI molecules to the donor material after absorption of light. ${ }^{10}$ All these properties make PDI derivatives an extremely attractive class of materials for use in organic photovoltaics as electron acceptor materials.

As the poly-aromatic core in PDI derivatives is planar, as opposed to spherical for fullerene derivatives, the performance of the devices is expected to depend on proper packing of the perylene moieties so that the $\pi$-orbitals can interact with each other. ${ }^{10}$ A common problem with small molecules is their tendency to rapidly crystallize, ${ }^{23,24}$ which limits their usefulness in applications involving thin films by yielding films of poor quality, with polycrystalline topologies constituted of small domains separated by grain boundaries that limit the long-range transport of electrons by acting as electron traps. ${ }^{25}$ Annealing conditions must thus be screened thoroughly to find the conditions that will give optimal film morphologies and limit grain boundaries.

An alternative approach consists in designing PDI derivatives (or electron acceptor materials in general) that form thin films that remain amorphous. ${ }^{26,27}$ While amorphous solids possess no long-range periodical order, intermolecular interactions, such as the $\pi$-stacking of aromatic moieties, can nonetheless be present and regulate to a certain degree the organization at the molecular level, with a continuous material that is exempt of grain boundaries.

As with the majority of small molecules, most PDI derivatives readily crystallize $^{26,27}$ However, it was demonstrated that strategic molecular design can hinder the process of crystallization, resulting in molecular materials that can remain in the amorphous state for extended (sometimes indefinite) periods of time. This class of materials are known as molecular glasses, or amorphous molecular materials, and combine the monodisperse nature of small molecules with the processability of polymers. ${ }^{28-30}$ As typically, compounds designed to form glasses possess bulky, non-planar and irregular shapes, and generally interact weakly with neighbouring molecules, ${ }^{31}$ designing PDI derivatives that can form glasses despite their planar perylene core and that can interact reliably by pi-stacking in the amorphous state is expected to be challenging. However, approaches where glass-forming derivatives of chromophores are synthesized by functionalization with peripheral groups have been reported in the literature. ${ }^{32-35}$ Mexylaminotriazines are one such family of glass-forming materials that usually show outstanding glassforming ability, high kinetic stability towards crystallization, and glass transition temperature $\left(\mathrm{T}_{\mathrm{g}}\right)$ values that can be modulated by tuning their molecular structures. ${ }^{36-38}$ Glassforming mexylaminotriazine derivatives can bear functional groups that can be bonded in a covalent fashion to chromophores, thereby yielding adducts that can remain indefinitely in the amorphous state at operating temperatures, while preserving the optical and electronic properties of the chromophore with minimal perturbation. This approach was demonstrated with a series of azobenzene dyes, with which glass-forming adducts were generated using a simple, efficient and high-yielding procedure. ${ }^{39-40}$

In the present work, four glass-forming PDI derivatives containing mexylaminotriazine groups in the bay position were synthesized, characterized, and incorporated into organic PV cells with P3HT as donor material. The PDI glasses synthesized feature two different imide groups, 2,6diisopropylphenyl and n-octyl, and two different bay substituents, bromo and pyrrolidinyl, to study the impact of steric bulk and electronics on device performance. All four acceptor materials investigated showed the ability to spontaneously form stable glasses that did not crystallize upon heating or operation of the devices, and all materials showed photovoltaic activity, with device efficiencies with P3HT as donor ranging from 0.2 to $0.6 \%$. These values are comparable to most values previously reported for PV cells using P3HT and PDI derivatives containing a single perylene moiety, ${ }^{10,41}$ and are reasonably close to the highest values reached so far for such systems (close to 1\%). ${ }^{21,42}$ Interestingly, the performances of the devices has been found to be independent on the electronics of the acceptor materials, with both bromo and pyrrolidinyl series giving similar results. On the other hand, the octyl imide series showed efficiency 3 times greater than their sterically hindered 2,6diisopropylphenyl imide analogues. This is believed to be due to the 2,6-diisopropylphenyl groups shielding the perylene core and preventing efficient stacking of the perylene moieties, thereby impeding electron transport. While the P3HT portion of the bulk heterojunction is semi-crystalline, the PDI domains remain amorphous, and the results reported herein show that the electron transport over long range required for current generation is possible in the amorphous state and yields performances comparable to that of crystalline materials.

\section{Experimental}

\subsection{Materials}

2-Methylamino-4-mexylamino-6-(4-mercaptophenyl)amino-

1,3,5-triazine (1), ${ }^{37} \quad$ N,N'-bis(2,6-diisopropylphenyl)-2,7dibromo-3,4,9,0-perylenetetracarboxylic diimide (2a), ${ }^{43}$ and N,N'-dioctyl-2,7-dibromo-3,4,9,0-perylenetetracarboxylic diimide (2b), ${ }^{44}$ were prepared according to the literature. Pyrrolidine was purchased from Sigma-Aldrich, and all other solvents and reagents were purchased from Caledon Labs. All reagents were used without further purification. Regioregular poly (3-hexylthiophene-2,5-diyl (P3HT) used as electron donor was purchased from Rieke Metals. Molybdenum oxide used as hole transport layer was purchased from Alfa Aesar. $\mathrm{ZnO}$ as electron transporting material was synthesized by the sol-gel method reported in the literature. ${ }^{45}$ The Indium tin oxide (ITO) glasses used as substrates were purchased from Luminescence Technology Corporation, which has ITO film thickness about $135 \pm 15 \mathrm{~nm}$, and sheet resistance is $15 \Omega \mathrm{sq}^{-1}$. 
Glass transition temperatures were determined with a TA Instruments 2010 Differential Scanning Calorimeter calibrated with indium at a heating rate of $5{ }^{\circ} \mathrm{C} / \mathrm{min}$ from 30 to $250{ }^{\circ} \mathrm{C}$. Values were reported as the half-height of the heat capacity change averaged over two heating runs. For compounds 3a and 4a, values were averaged over heating runs on two different samples because of thermal degradation. FTIR spectra were acquired with thin films cast from $\mathrm{CH}_{2} \mathrm{Cl}_{2}$ on $\mathrm{KBr}$ windows using a Perkin-Elmer Spectrum 65 spectrometer. UV-visible absorption spectra were acquired using a Hewlett-Packard 8453 spectrometer or a Olid ${ }^{\circledR}$ HP8452 Diode Array Spectrometer. NMR spectra were acquired on either a $400 \mathrm{MHz}$ Bruker AV400 or on a 300 $\mathrm{MHz}$ Varian Oxford spectrometer. Luminescence was measured with a USB2000-Ocean Optics spectrometer. XRD were obtained on P3HT/PDI films using an Xpert Pro Philips powder X-ray diffractometer.

\subsection{Synthesis}

\subsubsection{Synthesis of Compound $3 a$.}

A mixture of tetrahydrofuran $(800 \mathrm{~mL})$ and $\mathrm{K}_{2} \mathrm{CO}_{3}(11.1 \mathrm{~g}$, $80.0 \mathrm{mmol}$ ) in a round-bottomed flask was stirred and deoxygenated under nitrogen atmosphere for $30 \mathrm{~min}$. Next, compound 2a (14.0 g, $16.0 \mathrm{mmol}$ ) and glass 1 (7.05 g, 20.0 mmol) were added and the reaction mixture was stirred at room temperature for 3 days. THF was removed under reduced pressure and the crude product was purified on a short silica pad eluting with $100 \%$ dichloromethane initially to remove unreacted staring material. After collecting the fractions containing the starting material, the eluent was switched to DCM/EtOAc (80:20). $12.6 \mathrm{~g}$ of pure dark red product was obtained (11.1 mmol, $69 \%)$. $\mathrm{T}_{\mathrm{g}} 206{ }^{\circ} \mathrm{C}$; FTIR $\left(\mathrm{CH}_{2} \mathrm{Cl}_{2} / \mathrm{KBr}\right)$ 3420, 3346, 3195, 3102, 3065, 3027, 2964, 2930, 2869, 1709, 1669, 1621, 1586, 1559, 1538, 1518, 1497, 1457, 1444, 1430, 1413, 1388, 1363, 1335, 1306, 1242, 1198, 1181, 1148, 1094, 1057, 1040, 1013, 995, 969, 937, 919, 885, 859, 838, 809, 793, 770, 749, 741, 714, 698, $668 \mathrm{~cm}^{-1} ;{ }^{1} \mathrm{H}$ NMR (400 MHz, DMSO-d $\left.d_{6}, 363 \mathrm{~K}\right): \delta 9.64\left(\mathrm{~d},{ }^{3} J=8.3 \mathrm{~Hz}\right.$, 1H), 9.04 (br s, $1 \mathrm{H}), 8.89$ (m, 2H), 8.84 (d, $\left.{ }^{3} \mathrm{~J}=8.3 \mathrm{~Hz}, 1 \mathrm{H}\right)$, 8.70 (d, $\left.{ }^{3} \mathrm{~J}=8.1 \mathrm{~Hz}, 1 \mathrm{H}\right), 8.56$ (br s, $\left.1 \mathrm{H}\right), 8.38$ (br s, $1 \mathrm{H}$ ), 7.93 (d, $\left.{ }^{3} \mathrm{~J}=8.6 \mathrm{~Hz}, 2 \mathrm{H}\right), 7.47(\mathrm{~m}, 4 \mathrm{H}), 7.36\left(\mathrm{~d},{ }^{3} \mathrm{~J}=7.6 \mathrm{~Hz}, 2 \mathrm{H}\right)$, 7.32 (s, 2H), 7.30 (d, $\left.{ }^{3} J=7.8 \mathrm{~Hz}, 2 \mathrm{H}\right), 6.63$ (br s, $\left.1 \mathrm{H}\right), 6.57$ (s, $1 \mathrm{H}), 2.85$ (s, 3H), $2.80\left(\mathrm{~m},{ }^{3} J=6.8 \mathrm{~Hz}, 2 \mathrm{H}\right), 2.71\left(\mathrm{~m},{ }^{3} J=6.8\right.$ $\mathrm{Hz}, 2 \mathrm{H}), 2.18$ (s, 6H), 1.12 (d, $\left.{ }^{3} J=6.8 \mathrm{~Hz}, 6 \mathrm{H}\right), 1.11$ (d, ${ }^{3} J=$ $6.8 \mathrm{~Hz}, 6 \mathrm{H}), 1.08$ (d, $\left.{ }^{3} J=6.8 \mathrm{~Hz}, 6 \mathrm{H}\right), 1.04\left(\mathrm{~d},{ }^{3} J=6.8 \mathrm{~Hz}\right.$, $6 \mathrm{H}) \mathrm{ppm} ;{ }^{13} \mathrm{C}$ NMR (75 MHz, DMSO- $d_{6}$ ): $\delta$ 166.4, 164.5, 164.4, 164.1, 163.2, 163.2, 162.6, 145.9, 145.8, 143.3, 141.4, 140.2 , 137.6, 137.5, 135.9, 133.2, 132.9, 132.2, 130.9, 129.8, $129.4,129.2,128.7,128.4,127.5,126.0,124.3,123.7,122.8$, 122.6, 122.2, 122.0, 121.1, 120.5, 118.3, 28.9, 27.7, 24.2, 21.5 ppm; UV-Vis $\left(\mathrm{CH}_{2} \mathrm{Cl}_{2}\right): \lambda_{\max }$ (ع) $548 \mathrm{~nm}$ (24 200); HRMS (MALDI, $\mathrm{MH}^{+}$) calcd. for $\mathrm{C}_{66} \mathrm{H}_{60} \mathrm{BrN}_{8} \mathrm{O}_{4} \mathrm{~S}(\mathrm{~m} / \mathrm{e})$ : 1139.3642, found: 1139.3649 .

2.2.2. Synthesis of Compound $3 b$.

Compound $\mathbf{3 b}$ was synthesized from precursor $\mathbf{2} \mathbf{b}$ and glass $\mathbf{1}$ following a procedure similar to that used for analogue $\mathbf{3 a}$. The crude product was purified on a short silica pad using AcOEt/Hexanes 1:1 as eluent. Yield: $68 \%$; $\mathrm{T}_{\mathrm{g}} 91{ }^{\circ} \mathrm{C}$; FTIR $\left(\mathrm{CH}_{2} \mathrm{Cl}_{2} / \mathrm{KBr}\right)$ 3341, 3187, 3085, 2954, 2925, 2869, 2853, 1698, 1659, 1588, 1553, 1518, 1498, 1433, 1415, 1395, 1349, 1333, 1303, 1238, 1178, 1097, 1036, 833, 806, 745, 693, 654 $\mathrm{cm}^{-1}$; ${ }^{1} \mathrm{H}$ NMR (400 MHz, $\left.\mathrm{CDCl}_{3}\right): \delta 9.46\left(\mathrm{~d},{ }^{3} \mathrm{~J}=7.8 \mathrm{~Hz}, 1 \mathrm{H}\right)$, 8.87 (s, $1 \mathrm{H}), 8.73(\mathrm{~m}, 1 \mathrm{H}), 8.65\left(\mathrm{~d},{ }^{3} J=7.8 \mathrm{~Hz}, 1 \mathrm{H}\right), 8.57(\mathrm{~m}$, 1H), 8.29 (m, 1H), 7.68 (br s, 2H), 7.37 (m, 2H), 7.37 (br s, 1H), 7.16 ( s, 1H), 7.06 (s, 2H), 6.64 (s, 1H), 5.27 (br s, 1H), 4.20 (br m, 2H), 4.07 (br m, 2H), 2.97 (s, 3H), 2.23 (s, 6H), 1.76 (br m, 2H), 1.65 (br m, 2H), 1.30 (m, 20H), 0.90 (m, 6H) ppm; $\left.{ }^{13} \mathrm{C} \mathrm{NMR} \mathrm{(75} \mathrm{MHz,} \mathrm{CDCl}_{3}\right): \delta 166.2,166.1,163.8$, $162.9,162.8,162.5,162.3,141.5,141.2,140.5,139.0,138.1$, 137.6, 135.6, 132.8, 132.6, 132.4, 131.9, 130.9, 130.0, 129.8, 129.1, 128.7, 128.3, 127.9, 126.6, 125.2, 124.6, 123.8, 123.5, 123.2, 122.6, 122.0, 121.6, 121.3, 120.7, 120.0, 117.9, 40.7, 31.8, 29.3, 28.0, 27.6, 27.2, 22.7, 21.4, 14.1 ppm; UV-Vis $\left(\mathrm{CH}_{2} \mathrm{Cl}_{2}\right): \lambda_{\max }(\varepsilon) 548 \mathrm{~nm}$ (17600); HRMS (MALDI, $\mathrm{MH}^{+}$) calcd. for $\mathrm{C}_{58} \mathrm{H}_{60} \mathrm{BrN}_{8} \mathrm{O}_{4} \mathrm{~S} \quad(m / e)$ : 1045.3620, found: 1045.3662.

\subsubsection{Synthesis of Compound $4 a$.}

In a round-bottomed flask equipped with a magnetic stirrer, a mixture of pyrrolidine $(2.5 \mathrm{~mL})$, THF $(10 \mathrm{~mL})$ and $\mathrm{K}_{2} \mathrm{CO}_{3}$ ( $0.078 \mathrm{~g}, 0.50 \mathrm{mmol}$ ) was degassed by sparging with nitrogen for $15 \mathrm{~min}$. Compound $3 a$ (0.500 g, $0.440 \mathrm{mmol}$ ) was added, then the reaction mixture was stirred at ambient temperature for $24 \mathrm{~h}$ under nitrogen atmosphere. The volatiles were removed under reduced pressure while keeping the water bath temperature under $50{ }^{\circ} \mathrm{C}$. The residue was redissolved in minimal AcOEt, insolubles were removed by filtration, and the filtrate was poured into hexanes. The precipitated product was collected by filtration, washed with hexanes and allowed to dry at $60{ }^{\circ} \mathrm{C}$ in an oven to yield $0.485 \mathrm{~g}$ pure green compound 4a $(0.429 \mathrm{mmol}, 98 \%) . \quad \mathrm{T}_{\mathrm{g}} 186 \quad{ }^{\circ} \mathrm{C} ; \quad \mathrm{IR}$ $\left(\mathrm{CH}_{2} \mathrm{Cl}_{2} / \mathrm{KBr}\right) 3915,3846,3821,3739,3689,3659,3621$, 3551, 3349, 3193, 3070, 2961, 2930, 2915, 2868, 1700, 1667, 1606, 1593, 1579, 1556, 1496, 1423, 1403, 1381, 1363, 1336, 1290, 1239, 1201, 1181, 1152, 1132, 1119, 1057, 1014, 965, 940, 917, 838, 809, 795, 773, 753, 739, 714, 691, 668, 601, 582, $537 \mathrm{~cm}^{-1}$; ${ }^{1} \mathrm{H}$ NMR (400 MHz, DMSO- $d_{6}, 363.15 \mathrm{~K}$ ): $\delta$ $8.99\left(\mathrm{~d},{ }^{3} \mathrm{~J}=8.6 \mathrm{~Hz}, 1 \mathrm{H}\right), 8.96$ (br s, $\left.1 \mathrm{H}\right), 8.65$ (d, ${ }^{3} J=8.1 \mathrm{~Hz}$, $1 \mathrm{H}), 8.59$ (s, $1 \mathrm{H}), 8.53$ (d, $\left.{ }^{3} J=8.6 \mathrm{~Hz}, 2 \mathrm{H}\right), 8.40$ (s, $\left.1 \mathrm{H}\right), 7.88$ (d, $\left.{ }^{3} J=8.6 \mathrm{~Hz}, 2 \mathrm{H}\right), 7.65\left(\mathrm{~d},{ }^{3} J=8.11 \mathrm{~Hz}, 1 \mathrm{H}\right), 7.47$ (m, 2H), $7.41\left(\mathrm{~d},{ }^{3} \mathrm{~J}=8.6 \mathrm{~Hz}, 2 \mathrm{H}\right), 7.35\left(\mathrm{~d},{ }^{3} J=7.8 \mathrm{~Hz}, 2 \mathrm{H}\right), 7.31$ (s, 2H), 7.29 (d, ${ }^{3} J=7.8 \mathrm{~Hz}, 2 \mathrm{H}$ ), 6.61 (br s, $1 \mathrm{H}$ ), 6.53 (s, $1 \mathrm{H}$ ), 3.36 (br s, 4H), 2.85 (d, $\left.{ }^{3} J=4.3 \mathrm{~Hz}, 3 \mathrm{H}\right), 2.78\left(\mathrm{~m},{ }^{3} J=6.8\right.$ $\mathrm{Hz}, 2 \mathrm{H}), 2.68\left(\mathrm{~m},{ }^{3} \mathrm{~J}=6.8 \mathrm{~Hz}, 2 \mathrm{H}\right), 2.14$ (s, 6H), 2.06 (br s, $4 \mathrm{H}), 1.13$ (d, $\left.{ }^{3} J=6.8 \mathrm{~Hz}, 6 \mathrm{H}\right), 1.11$ (d, $\left.{ }^{3} J=6.8 \mathrm{~Hz}, 6 \mathrm{H}\right), 1.08$ (d, $\left.{ }^{3} J=6.8 \mathrm{~Hz}, 6 \mathrm{H}\right), 1.04\left(\mathrm{~d},{ }^{3} J=6.8 \mathrm{~Hz}, 6 \mathrm{H}\right) ;{ }^{13} \mathrm{C}$ NMR $(75$ MHz, DMSO-d6): 165.9, 163.9, 163.6, 163.48, 163.41, 163.04, 162.8, 148.2, 145.4, 145.2, 141.9, 139.8, 137, 135.7, 134.6, 133.5, 131.4, 130.9, 130.8, 130.2, 129.3, 129.1, 128.4, 126.1, 125.5, 124.2, 123.7, 123.1, 122.2, 121.9, 121.7, 121.5, 120.5, 119.9, 117.7, 116.9, 114.1, 52.6, 28.5, 27.2, 25.3, 20.9 
ppm; UV-Vis $\left(\mathrm{CH}_{2} \mathrm{Cl}_{2}\right): \lambda_{\max }(\varepsilon) 435 \mathrm{~nm}$ (13 700), $664 \mathrm{~nm}(22$ 400); HRMS (MALDI, $\mathrm{MH}^{+}$) calcd. for $\mathrm{C}_{70} \mathrm{H}_{68} \mathrm{~N}_{9} \mathrm{O}_{4} \mathrm{~S}(\mathrm{~m} / \mathrm{e})$ : 1130.5115, found: 1130.5124 .

\subsubsection{Synthesis of Compound $4 b$.}

Compound $\mathbf{4 b}$ was synthesized from precursor $\mathbf{2 b}$ and glass $\mathbf{1}$ following a procedure similar to that used for analogue $\mathbf{4 a}$. The crude product was purified on a short silica pad using AcOEt/Hexanes 1:1 as eluent. Yield: $82 \%$; $\mathrm{T}_{\mathrm{g}} 86{ }^{\circ} \mathrm{C}$; FTIR $\left(\mathrm{CH}_{2} \mathrm{Cl}_{2} / \mathrm{KBr}\right)$ 3333, 3181, 2954, 2923, 2852, 1692, 1653, 1590, 1579, 1554, 1500, 1431, 1415, 1397, 1346, 1334, 1286, 1238, 1178, 1127, 1099, 1032, 863, 837, 806, 749, 708, 658 $\mathrm{cm}^{-1}$; ${ }^{1} \mathrm{H}$ NMR (400 MHz, $\mathrm{CDCl}_{3}$ ): $\delta 8.49$ (br m, $\left.1 \mathrm{H}\right), 8.46$ (d, $\left.{ }^{3} J=7.8 \mathrm{~Hz}, 1 \mathrm{H}\right), 8.38$ (s, 1H), 8.34 (d, $\left.{ }^{3} J=7.8 \mathrm{~Hz}, 1 \mathrm{H}\right), 8.15$ (br m, 1H), 7.55 (br s, 3H), 7.34 (d, ${ }^{3} J=7.8 \mathrm{~Hz}, 1 \mathrm{H}$ ), 7.25 (br s, 2H), 7.10 (br s, 2H), 6.99 (br s, 1H), 6.55 (s, 1H), 5.36 (br s, 1H), 4.12 (br m, 2H), 4.00 (br m, 2H), 3.61 (br s, 1H), 2.76 (s, 3H), 2.67 (br s, 1H), 2.14 (s, 6H), 1.99 (br s, 1H), 1.89 (br s, 1H), 1.67 (br m, 2H), 1.58 (br m, 2H), 1.20 (m, 20H), 0.80 (m, 6H) ppm; ${ }^{13} \mathrm{C}$ NMR (75 $\left.\mathrm{MHz}, \mathrm{CDCl}_{3}\right): \delta$ 166.5, 164.1, 163.9, 163.8, 163.6, 163.2, 148.1, 140.7, 138.3, 136.4, 135.6, 135.1, 134.2, 133.0, 132.7, 132.0, 131.8, 129.4, 129.3, 128.8, 128.4, 127.1, 125.8, 125.3, 124.8, 123.9, 122.8, 122.0, 121.2, 120.7, 120.6, 120.4, 118.3, 115.8, 52.6, 40.7, 31.8, 29.4, 29.2, 28.1, 27.7, 27.2, 25.8, 22.6, 21.4, $14.1 \mathrm{ppm}$; UV-Vis $\left(\mathrm{CH}_{2} \mathrm{Cl}_{2}\right)$ : $\lambda_{\max }(\varepsilon) 433 \mathrm{~nm}$ (11 400), $656 \mathrm{~nm}$ (15 800); HRMS (MALDI, $\mathrm{MH}^{+}$) calcd. for $\mathrm{C}_{62} \mathrm{H}_{68} \mathrm{~N}_{9} \mathrm{O}_{4} \mathrm{~S}(\mathrm{~m} / \mathrm{e})$ : 1034.5109, found: 1034.5135.

\subsubsection{Sample One-Pot Procedure: Synthesis of Compound 4a.}

In a round-bottomed flask equipped with a magnetic stirrer, a suspension of $\mathrm{K}_{2} \mathrm{CO}_{3}(1.59 \mathrm{~g}, 11.5 \mathrm{mmol})$ in THF $(50 \mathrm{~mL})$ was degassed by sparging with nitrogen for $15 \mathrm{~min}$. N,N'Bis(2,6-diisopropylphenyl)-2,7-dibromo-3,4,9,0-

perylenetetracarboxylic diimide 2a $(2.00 \mathrm{~g}, 2.30 \mathrm{mmol})$ and 2-methylamino-4-mexylamino-6-(4-mercaptophenyl)amino1,3,5-triazine 1 (1.01 g, $2.88 \mathrm{mmol})$ were added simultaneously, and the mixture was stirred $48 \mathrm{~h}$ at ambient temperature under nitrogen atmosphere, at which point pyrrolidine $(5 \mathrm{~mL})$ was added and stirring was continued another $48 \mathrm{~h}$. The volatiles were evaporated under vacuum while maintaining the water bath temperature below $50{ }^{\circ} \mathrm{C}$, the residue was redissolved in $\mathrm{CH}_{2} \mathrm{Cl}_{2}$ and purified by filtration on a short silica pad with AcOEt/hexanes (3:7 then 7:3) to yield, after complete drying, $1.66 \mathrm{~g}$ compound 4a (1.47 mmol, $64 \%)$. Spectral data was identical to that obtained for compound 4a prepared from pure compound $3 \mathbf{a}$.

\subsection{Cyclic Voltammetry}

Cyclic voltammograms were recorded using an EG\&G Model 263 potentiostat connected with three electrodes: working electrode (glassy carbon-carbon), reference electrode (Ag/AgCl (in 3M NaCl) and counter or auxiliary electrode (Pt) in a $0.1 \quad \mathrm{M}$ solution of tetrabutylammonium hexafluorophosphate in acetonitrile at a scan rate of $100 \mathrm{mVs}^{-1}$ with $\mathrm{N}_{2}$ gas bubbling. Ferrocene was used as internal standard.

\subsection{Atomic Force Microscopy}

The morphology of nanocomposite P3HT/PDI films was characterized using an Ambios multimode Atomic force Microscope (AFM) in tapping mode with $300 \mathrm{KHz}$ resonant frequency cantilever.

\subsection{Device Fabrication and Characterization}

The ITO substrates were either patterned with $0.1 \mathrm{M} \mathrm{HCl}$ and zinc dust for 10 minutes and thoroughly washed with water, or pre-patterned as purchased. The patterned ITO substrates were cleaned consecutively in an ultrasonic bath with detergent powder, distilled water, acetone and isopropyl alcohol for 10 minutes each and finally dried with air. The substrates were heated at approximately $100{ }^{\circ} \mathrm{C}$ for 5 minutes. The dried substrates were further cleaned with a plasma cleaner for 15 minutes. $\mathrm{ZnO}$ precursor gel was spin-coated at a rate of $3000 \mathrm{rpm}$ for $40 \mathrm{sec}$ under ambient conditions. The glass substrates coated with $\mathrm{ZnO}$ were transferred on a hotplate and baked at $150{ }^{\circ} \mathrm{C}$ for 30 minutes. The thickness of $\mathrm{ZnO}$ was approximately $30 \mathrm{~nm}$. The blend solutions of P3HT and PDI glasses 3-4 were prepared in dichlorobenzene in a fixed ratio (1:1,1:2 and 2:1) by weight and stirred for $24 \mathrm{~h}$ at $50{ }^{\circ} \mathrm{C}$. The solution was filtered through a $0.45 \mu \mathrm{m}$ pore sized poly(tetrafluoroethylene) (PTFE) filter. The active layer was spin-coated at $1500 \mathrm{rpm}$ and annealed at $110{ }^{\circ} \mathrm{C}$ for 10 minutes. The thickness of the active layer was measured to range from 150-180 nm with a Sloan Dektak II profilometer. The top and bottom electrodes of the devices were cleaned with a cotton stick soaked with chloroform to make contacts. Finally, $5 \mathrm{~nm}$ of $\mathrm{MoO}_{3}$ and $100 \mathrm{~nm}$ of Ag were deposited with deposition rates of $0.5 \mathrm{~A} / \mathrm{s}$ and $1.5 \mathrm{~A} / \mathrm{s}$, respectively, on all the devices using a physical vapour deposition system (PVD) under high vacuum at a pressure of $1 \times 10^{-6} \mathrm{mBar}$. The active area of the device was $0.2 \mathrm{~cm}^{2}$. The device structure and energy alignment is shown in Figure 1. Current densityvoltage (J-V) measurements were carried out using a Keithley 4200-SCS in the dark and under illumination. All the photovoltaic parameters of the inverted cells were measured at ambient conditions using a Xenon light with an intensity of $100 \mathrm{~mW} / \mathrm{cm}^{2}$ calibrated with an AM 1.5 solar simulator. ${ }^{46}$ Mobility measurements were performed with diodes of compounds 3-4 that were prepared in a similar fashion, using solutions of pure PDI glasses 3-4 instead of P3HT/PDI-glass blends. The electron mobility for each diode was calculated using Mott-Gurney space-charge-limited current (SCLC) equation. $^{49}$ 
(a)

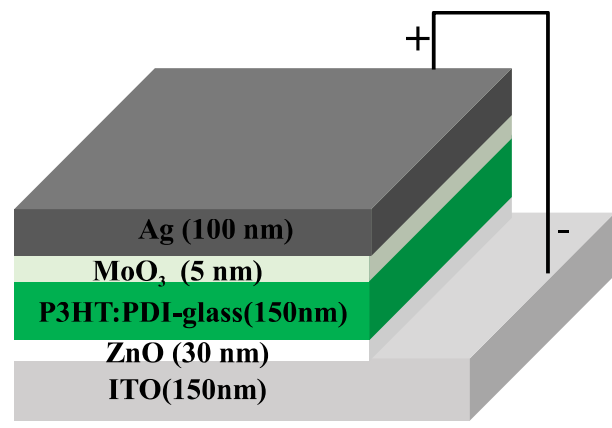

(b)

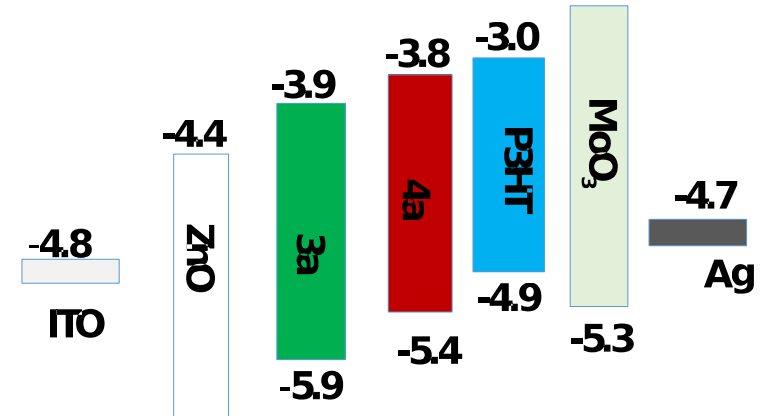

$-7.6$

Figure 1. Device structure and energy level alignment of device components.

\section{Results and Discussion}

\subsection{Synthesis of PDI glasses 3-4}

Initial attempts to functionalize the imide groups of the PDI core with glass-inducing mexylaminotriazine moieties were unsuccessful, as the products showed very low solubility in any solvent. For these reasons, N,N'-Bis(2,6diisopropylphenyl)-2,7-dibromo-3,4,9,0-

perylenetetracarboxylic diimide $\mathbf{2 a}$ and N,N'-dioctyl-2,7dibromo-3,4,9,0-perylenetetracarboxylic diimide $\mathbf{2 b}$ were selected as precursors because they are known to show appreciable solubility in most organic solvents, and they can be further functionalized by substitution of the bromo groups at the 2-and 7-positions. Among possible nucleophiles, thiolates and secondary amines are the most appealing to functionalize precursors 2a-b, because the reactions can be carried out under mild conditions, with roughly stoichiometric amounts of reagent, and with some control over the degree of substitution on the PDI. As a glass with a thiol group has already been reported by our group (glass $\mathbf{1}$ ) and can be easily synthesized in high yield from simple precursors, it constituted the most elegant solution for the synthesis of glass-forming PDI derivatives. Furthermore, PDI derivatives with amino bay substituents undergo a significant shift in their absorption, while sulfide substituents impact the electronic properties of the conjugated system in a more subtle fashion, thereby allowing a higher tunability through the introduction of additional substituents.

Dibromo precursors 2a-b could be substituted only at the 2position of the PDI core with thiol-functionalized glass $\mathbf{1}$ in the presence of $\mathrm{K}_{2} \mathrm{CO}_{3}$ with a slight excess of glass $\mathbf{1}$ in THF at ambient temperature to give monoadducts $\mathbf{3 a - b}$ as major products, along with small quantities of unreacted precursors 2a-b and the corresponding bis-adducts, which are only sparingly soluble in most organic solvents (and therefore not promising candidates for solution-processed PV cells). Both products could be easily purified by filtration on a short silica pad with AcOEt/ $\mathrm{CH}_{2} \mathrm{Cl}_{2}$ (1:4) for compound 3a, or with AcOEt/Hexanes (1:1) for compound $\mathbf{3 b}$, to give after drying pure products 3a-b in $69 \%$ and $68 \%$ yield, respectively (Scheme 1). $\neq$

\section{Scheme 1.}
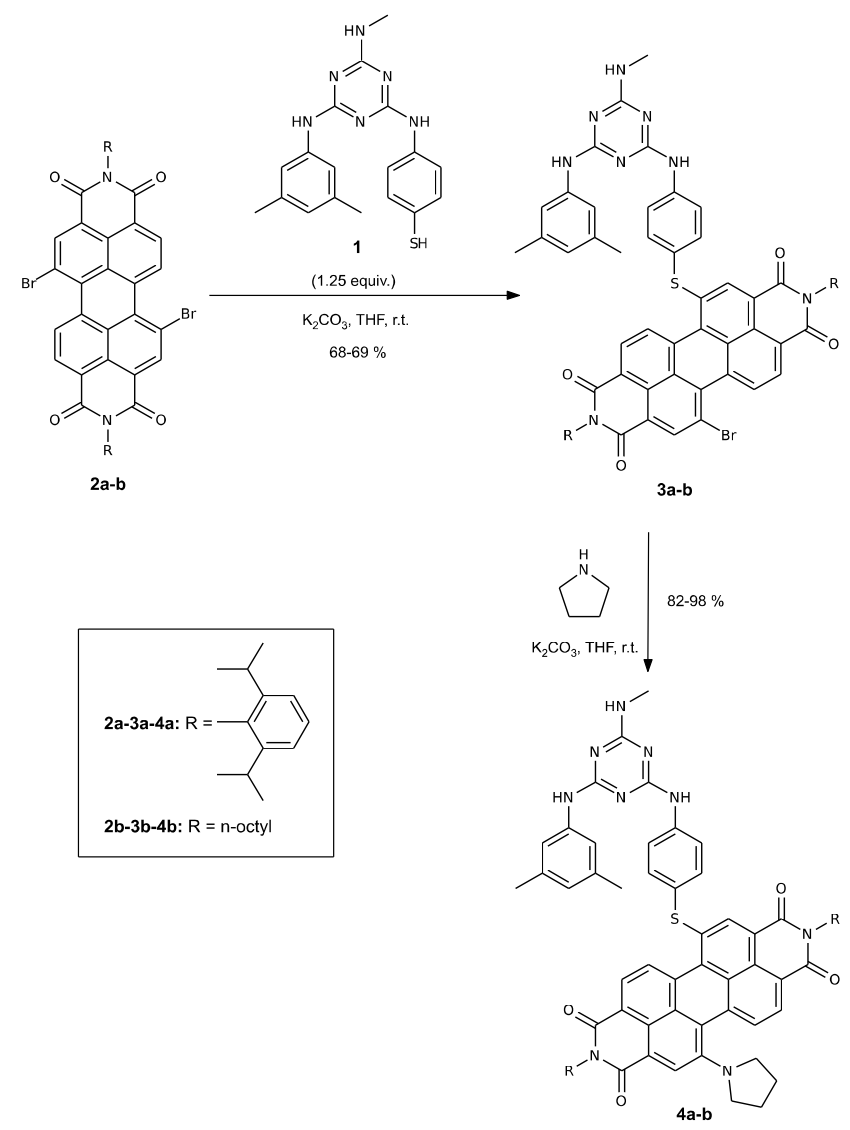

As compounds 3a-b are still substituted with a bromo group, other nucleophiles can be introduced at the 7-position of the perylene ring system to tune its electronics, and its absorption range. An amino substituent was selected because these 
strongly electron-donating groups are known to result into strongly red-shifted absorption maxima (more than $100 \mathrm{~nm}$ ). These two series of acceptor materials can harvest different portions of the visible range to complement absorption from donor materials. Analogues 4a-b substituted with a pyrrolidinyl group were synthesized from compounds $\mathbf{3 a - b}$ by reaction with pyrrolidine in THF at ambient temperature in 82-98\% yields (Scheme 1). Alternatively, compounds 4a-b can also be synthesized directly from precursors $2 \mathbf{2 a - b}$ in a one-pot procedure where both bromo groups are displaced sequentially with glass $\mathbf{1}$ and pyrrolidine, followed by a single purification step by chromatography.

\subsection{Physical Properties of PDI Glasses 3-4}

As with other dyes functionalized with mexylaminotriazine units previously reported, compounds 3-4 readily form glassy solids upon drying from solution that remain amorphous over time. Differential Scanning Calorimetry (DSC) confirmed that compounds 3-4 indeed show glass transitions. Bulky bis(2,6diisopropylphenyl) imides $\mathbf{3 a}$ and $\mathbf{4 a}$ show very high $\mathrm{T}_{\mathrm{g}}$ values ranging from $186{ }^{\circ} \mathrm{C}$ to $206{ }^{\circ} \mathrm{C}$ (Table 1 ), while more flexible dioctyl imides $\mathbf{3 b}$ and $\mathbf{4 b}$ show $\mathrm{T}_{\mathrm{g}}$ values between $86-$ $91{ }^{\circ} \mathrm{C}$ (sample DSC curves for all four compounds are shown in Figure S1, Supporting Information).

The structural features that impacts $T_{g}$ the most in this series are the nature of the imide groups. Derivatives $\mathbf{3 a - 4 a}$ with rigid and bulky 2,6-diisopropylphenyl groups showed $\mathrm{T}_{\mathrm{g}}$ values over $100{ }^{\circ} \mathrm{C}$ higher than their analogues with flexible octyl chains $\mathbf{3 b}-\mathbf{4 b}$, which is likely attributable to the available degrees of freedom of linear alkyl chains, considering that the rest of the molecule is relatively rigid: the perylene ring system is fused, and triazine amino groups are strongly conjugated. As a result, compound 3a, for instance, possesses few unhindered rotational degrees of freedom, making it difficult to generate free volume through molecular motion. Pyrrolidinyl-substituted glasses $\mathbf{4 a}$ and $\mathbf{4 b}$ also undergo glass transition at slightly lower temperatures than their bromo-substituted precursors 3a-b, because of the higher flexibility of the pyrrolidine ring.

Table 1. Glass transition temperature $\left(T_{g}\right)$ values for PDIfunctionalized glasses 3-4.

\begin{tabular}{ll}
\hline Compound & $\mathbf{T}_{\mathbf{g}}\left({ }^{\circ} \mathbf{C}\right)$ \\
\hline 3a & 206 \\
\hline $3 \mathbf{b}$ & 91 \\
\hline $\mathbf{4 a}$ & 196 \\
\hline $\mathbf{4 b}$ & 86 \\
\hline
\end{tabular}

No crystallization was observed upon heating for compounds $\mathbf{3 - 4}$, but in the case of glasses $\mathbf{3 a}$ and $\mathbf{4 a}$, heating the samples past their $\mathrm{T}_{\mathrm{g}}$ resulted in partial decomposition, which was confirmed by ${ }^{1} \mathrm{H}$ NMR spectroscopy. The DSC measurements thus had to be performed on different samples to confirm the $\mathrm{T}_{\mathrm{g}}$ values, as they decreased steadily upon repeated heating cycles. Compounds $\mathbf{3 b}$ and $\mathbf{4 b}$ could be safely heated up to $200{ }^{\circ} \mathrm{C}$, and did not show any signs of crystallization upon heating. While the absence of undesirable crystallization on heating could not be verified reliably for compounds $\mathbf{3 a}$ and 4a, they undergo glass transition at temperatures so high that crystallization will not occur under standard operating conditions. To confirm this, thin films of glasses 3-4 were prepared by spin coating from $\mathrm{CH}_{2} \mathrm{Cl}_{2}$ solution, and annealed at $110{ }^{\circ} \mathrm{C}$ for 10 minutes. The films were then studied by atomic force microscopy (AFM) (Figure S2) and X-ray diffraction (XRD) (Figure S3), and compared to films before annealing. In all cases, spin-coating yielded amorphous and topologically smooth films, and annealing did not result in any changes in either the phase or the topology of the films.

As with all PDI derivatives, glasses 3-4 absorb strongly in the visible range. UV-visible absorption spectra of compounds 34 were thus recorded in $\mathrm{CH}_{2} \mathrm{Cl}_{2}$ solution (Figure 2a). Absorption maxima and extinction coefficients are reported in Table 2. It can be observed that the presence of the mexylaminotriazine moieties bonded to the PDI through a sulfide group results in a slight red shift, while aminosubstituted analogues 4a-b instead shows two absorption bands, one near $430 \mathrm{~nm}$, and a larger one near $660 \mathrm{~nm}$, which is characteristic of PDI dyes with amino bay substituents. Unlike precursors 2a-b, however, no significant fluorescence could be observed from compounds 3-4 in solution, possibly a result of self-quenching by the triazine group.

The UV-visible spectra of thin films of glasses 3-4 prepared by spin coating from $\mathrm{CH}_{2} \mathrm{Cl}_{2}$ solution were recorded (Figure 2b). Their absorption maxima are listed in Table 2. The absorption bands for monoadducts $3 \mathbf{a}$ and $\mathbf{4 a}$ underwent a slight red shift, which is likely a consequence of a higherpolarity environment relative to solution. Compounds $\mathbf{3 b}$ and 4b, on the other hand, showed larger absorption shifts, from 548 to $564 \mathrm{~nm}$ for compound 3b, and from 433 to $443 \mathrm{~nm}$ for compound $\mathbf{4 b}$. Moreover, the absorption bands of compounds 3b-4b showed a more important broadening between solution and solid state than those of compounds $\mathbf{3 a - 4 a .}$

Table 2. Absortion bands and HOMO-LUMO energy gaps for PDI-functionalized glasses $\mathbf{3 - 4}$ in $\mathrm{CH}_{2} \mathrm{Cl}_{2}$ solution $(50 \mu \mathrm{M})$ and as solid thin films.

\begin{tabular}{lllll}
\hline $\begin{array}{l}\text { Compoun } \\
\mathbf{d}\end{array}$ & $\begin{array}{l}\lambda_{\max } \\
\left(\mathbf{C H} \mathbf{C l}_{2}\right) \\
(\mathbf{n m})\end{array}$ & $\begin{array}{l}\boldsymbol{\varepsilon}\left(\mathbf{C H}_{2} \mathbf{C l}_{2}\right) \\
\left(\mathbf{c m}^{-1} \mathbf{M}^{-1}\right)\end{array}$ & $\begin{array}{l}\lambda_{\max }(\mathbf{n m}) \\
(\mathbf{f i l m})\end{array}$ & $\begin{array}{l}\mathbf{E}_{\text {номо- }} \\
\text { Lumo }(\mathbf{e V})^{\mathbf{a}}\end{array}$ \\
\hline 3a & 548 & 24200 & 554 & 1.96 \\
\hline $\mathbf{3 b}$ & 548 & 17600 & 564 & 1.80 \\
\hline $\mathbf{4 a}$ & 435 & 13700 & 436 & \\
\hline & 664 & 22400 & 668 & 1.63 \\
\hline $\mathbf{4 b}$ & 433 & 11400 & 443 & \\
\hline & 656 & 15800 & 658 & 1.61 \\
\hline
\end{tabular}


a) HOMO-LUMO gaps were calculated from $\mathrm{E}_{\text {Hомо-Luмо }}=$ $1240 / \lambda_{\text {onset }}$

These observations hint towards more efficient formation of $\pi$-stacked aggregates in the solid state. Compounds 3a-4a possess extremely bulky 2,6-diisopropylphenyl imide substituents, which are perpendicular to the PDI ring system because of the isopropyl groups in the ortho positions. As a result, the PDI core is shielded from interacting with the PDI moieties from other molecules. On the other hand, linear octyl chains generate less steric hindrance around the PDI group, leading to more efficient $\pi$-stacking. Again, no noticeable fluorescence was observed on thin films of dyes 3-4.

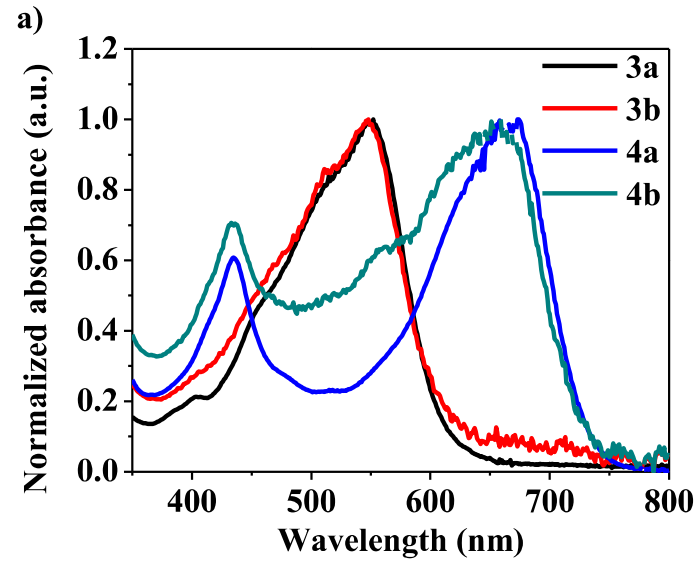

b)

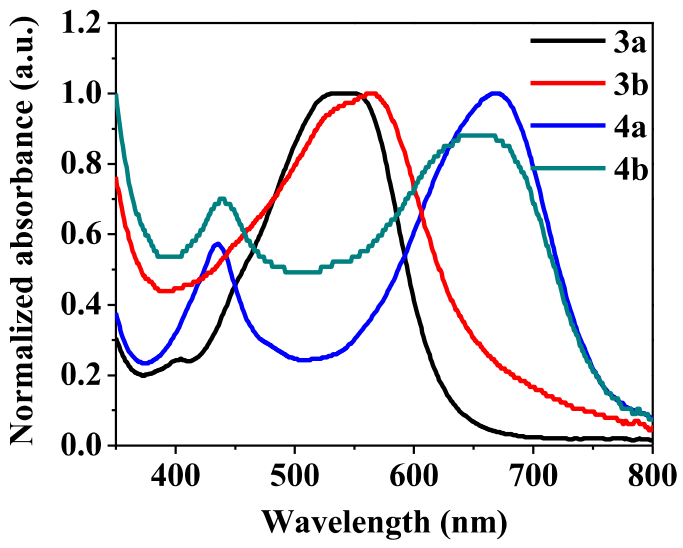

Figure 2. UV-Visible spectra of PDI glass derivatives 3-4. a) $50 \mu \mathrm{M}$ solution in $\mathrm{CH}_{2} \mathrm{Cl}_{2}$; b) thin solid films spin-coated from $\mathrm{CH}_{2} \mathrm{Cl}_{2}$.

The reduction potentials of compounds 3-4 were measured by cyclic voltammetry. $0.01 \mathrm{M}$ solutions of PDI glasses 3-4 and $0.1 \mathrm{M} n-\mathrm{Bu}_{4} \mathrm{NPF}_{6}$ were prepared in acetonitrile. The electrolytic cell was previously cleaned with acetonitrile, half filled with $0.1 \mathrm{M} n-\mathrm{Bu}_{4} \mathrm{NPF}_{6}$ and outgassed with bubbling $\mathrm{N}_{2}$. A small amount of ferrocene was added to it as internal standard and stirred. The starting potential was higher than the reference electrode potential to ensure that the species of interest was completely oxidized. The solution was scanned at a rate of $100 \mathrm{mVs}^{-1}$. Cyclic voltammograms are shown in Figure S4 (Supporting Information). In all cases, a single reversible reduction signal was observed, with compound $\mathbf{3 b}$ showing an additional small oxidation signal. The values for the reduction potentials are listed in Table 3. From the reduction potentials, the LUMO energy levels for compounds 3-4 could be calculated by comparison to ferrocene $(-4.8 \mathrm{eV})$ (Table 3). From the LUMO energy levels and the values for the HOMO-LUMO gaps measured by UV-visible spectroscopy, the HOMO levels could be calculated, and are listed in Table 3. HOMO and LUMO energy levels for compounds 3-4 are in agreement with published values for PDI derivatives substituted in the bay area: the HOMO and LUMO energy levels for 2,7-dibromo PDI derivatives are close to -6.1 and $-3.9 \mathrm{eV}$, respectively, while for more electron-rich 2,7-bis(pyrrolidinyl) analogues, these values are close to -5.2 and $-3.5 \mathrm{eV} .^{47}$ The impact of the imide groups was minimal, with bis(octyl) derivatives showing slightly higher LUMO levels and slightly lower HOMO-LUMO gaps, perhaps because of the formation of aggregates in solution. In comparison, the HOMO and LUMO levels of $\mathrm{PC}_{61} \mathrm{BM}$ are -6.1 and $-3.7 \mathrm{eV},{ }^{19}$ which is close to the LUMO energy levels of pyrrolidinyl derivatives $\mathbf{4 a - b}$.

Table 3. Reduction potentials and HOMO and LUMO energy levels for compounds 3-4. LUMO energy levels were measured by cyclic voltammetry, HOMO-LUMO gaps were measured by UV-visible spectroscopy, and LUMO energy levels were calculated from the HOMO levels and the energy gaps.

\begin{tabular}{lllll}
\hline $\begin{array}{l}\text { Compoun } \\
\mathbf{d}\end{array}$ & $\boldsymbol{E}^{\mathrm{red}} \mathbf{1 / 2}(\mathrm{V})$ & $\begin{array}{l}\mathbf{E}_{\text {Hомо }} \\
(\mathbf{e V})^{\mathbf{a}}\end{array}$ & $\begin{array}{l}\mathbf{E}_{\text {LUMo }} \\
(\mathbf{e V})^{\mathbf{b}}\end{array}$ & $\begin{array}{l}\text { E }_{\text {номо- }} \\
\text { LUмо }(\mathbf{e V})^{\mathbf{c}}\end{array}$ \\
\hline 3a & -0.32 & -5.88 & -3.92 & 1.96 \\
\hline $\mathbf{3 b}$ & -0.40 & -5.78 & -3.98 & 1.80 \\
\hline $\mathbf{4 a}$ & -0.50 & -5.43 & -3.80 & 1.63 \\
\hline $\mathbf{4 b}$ & -0.46 & -5.31 & -3.76 & 1.61 \\
\hline
\end{tabular}

a) Calculated from the LUMO levels and the HOMO-LUMO gaps.

b) Calculated from the reduction potentials measured by cyclic voltammetry with $\mathrm{E}_{\mathrm{LUMO}}=\mathrm{E}_{1 / 2}^{\mathrm{red}}-\mathrm{E}_{1 / 2}($ ferrocene $)+4.8$

c) Taken from Table 2.

Diodes incorporating compounds 3-4 were fabricated with the configuration ITO/ZnO/PDI-glass $/ \mathrm{MoO}_{3} / \mathrm{Ag}$ to measure the electron mobility of PDI glasses 3-4. Current-voltage curves were generated for each PDI glass derivative, and are shown in Figure S5 (Supporting Information). Electron mobility was calculated using the Mott-Gurney space-charge-limited current (SCLC) equation, ${ }^{49}$ and values are reported in Table 4 (details about the calculations can be found in Supporting Information and additional data is listed in Table S1). From Table 4, it can be observed that PDI glasses 3-4 show relatively low mobility values in the $10^{-8}$ to $10^{-6}$ range, possibly a consequence to the lack of long-range order associated with the amorphous state. Octyl-functionalized derivatives $\mathbf{3 b}$ and $\mathbf{4 b}$ were found to display mobilities one 
order of magnitude higher than their 2,6-diisopropylphenyl analogues 3a-4a, reinforcing the hypothesis that the less hindered octyl chains lead to stronger $\pi$-stacking between perylene moieties. Surprisingly, bromo derivatives 3a-b also showed mobilities nealy ten times higher than pyrrolidinyl analogues 4a-b, despite the latter showing smaller HOMOLUMO gaps. It is likely that the larger pyrrolidinyl groups also negatively impact interactions between the PDI groups in the solid state, leading to less efficient electron transport.

Table 4. Electron mobility values for PDI-functionalized glasses 3-4.

\begin{tabular}{ll}
\hline Compound & Mobility $\left(\mathbf{c m}^{2} \mathbf{V}^{-1} \mathbf{s}^{-1}\right)$ \\
\hline $3 \mathbf{a}$ & $1.29 \times 10^{-7}$ \\
\hline $3 \mathbf{b}$ & $4.00 \times 10^{-6}$ \\
\hline $\mathbf{4 a}$ & $6.34 \times 10^{-8}$ \\
\hline $\mathbf{4 b}$ & $3.30 \times 10^{-7}$ \\
\hline
\end{tabular}

3.3. Deposition and Characterization of Thin Films of P3HT Blends with PDI Glasses

Films of P3HT blends with PDI glasses 3-4 were cast in a 1:1 ratio from dichlorobenzene and annealed at $110{ }^{\circ} \mathrm{C}$ for 10 minutes. The normalized UV-Visible absorption spectra of the thin film blends of P3HT with PDI glasses 3-4 are shown in Figure 3 along with the spectra of both individual components. It can be observed that for bromo derivatives 3a$\mathbf{b}$, the contribution of the PDI acceptor to the absorption of the blend in the visible range is negligible, because of the overlap between the absorption bands of both components. In the case of pyrrolidinyl derivatives $\mathbf{4 a - b}$, additional shoulders corresponding to the absorption maxima of the PDI derivatives can be seen in the absorption band of the blend. This was more pronounced for compound 4a, where an additional band near $600 \mathrm{~nm}$ was observed.

The surface morphology of the blend films was studied by AFM. Figure 4 shows the surface topographic images for blends of P3HT with PDI-glass derivatives 3-4 in a 1:1 ratio after annealing at $110{ }^{\circ} \mathrm{C}$ for 10 minutes. The topographic images of the blends of P3HT with compounds 3-4 all show relatively smooth surfaces with root mean square roughness ranging from $26 \mathrm{~nm}$ for compound $3 \mathbf{b}$ to $41 \mathrm{~nm}$ for compound 4a. High surface roughness is typically associated with the presence of large aggregated features that decrease exciton dissociation and charge collection in the device and result in lower photocurrent and efficiency. ${ }^{20}$ The surface of blends of P3HT with dioctyl imide derivatives $\mathbf{3 b}$ and $\mathbf{4 b}$ are relatively smoother with root mean square roughness roughly $10 \mathrm{~nm}$ lower than their bis(2,6-diisopropylphenyl) analogues 3a and 4a. PDI derivatives with pyrrolidinyl bay substituents $4 \mathbf{4 a - b}$ also show higher roughness compared to their bromosubstituted analogues 3a-b, which is likely due to the higher steric hindrance of the pyrrolidinyl groups that impacts the

Figure 3. UV-vis absorption spectra of films of blends of a)

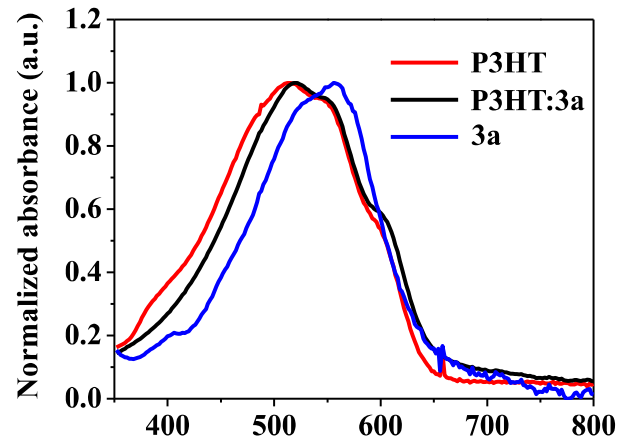

b) Wavelength $(\mathrm{nm})$
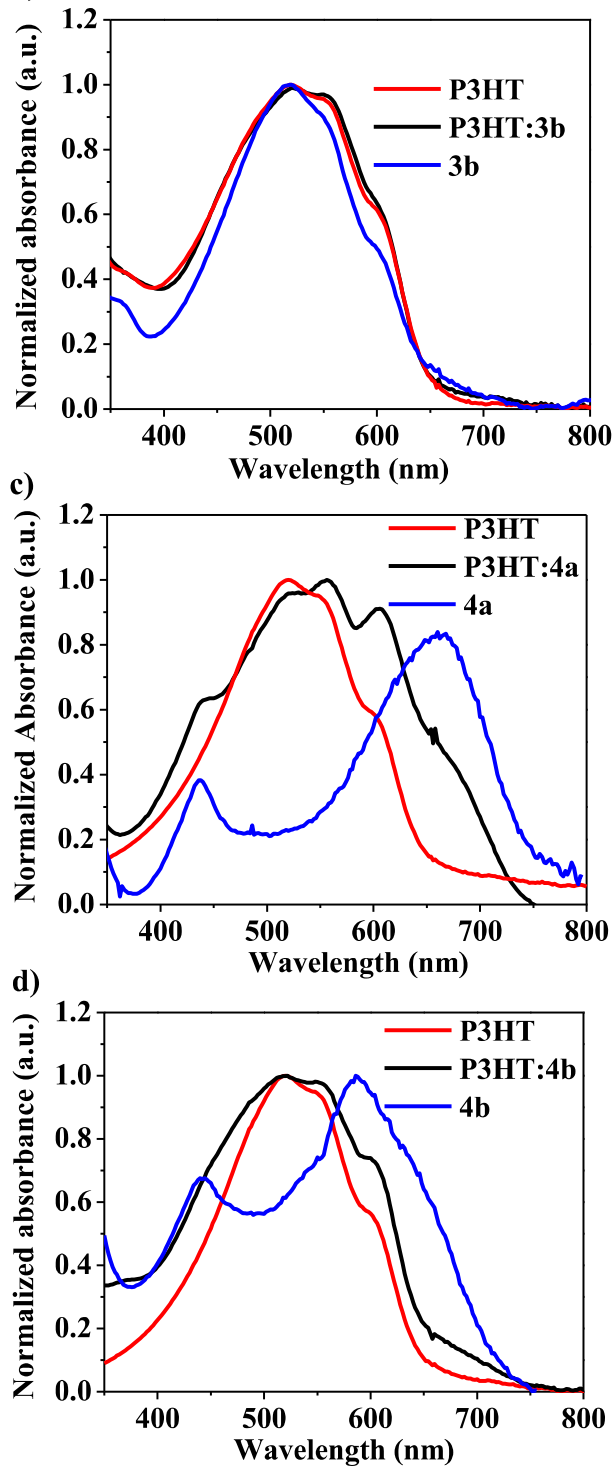

P3HT with PDI glasses 3-4. (a) 3a, (b) 3b, (c) 4a, and (d) $4 \mathbf{b}$.

Figure 4. AFM topographic images $(5 \mu \mathrm{m} \times 5 \mu \mathrm{m})$ for blends of P3HT with PDI glasses 3-4 after annealing at $110{ }^{\circ} \mathrm{C}$ for 10 minutes; (a) 3a, (b) 4a, (c) 3b, and (d) $4 \mathbf{b}$. 

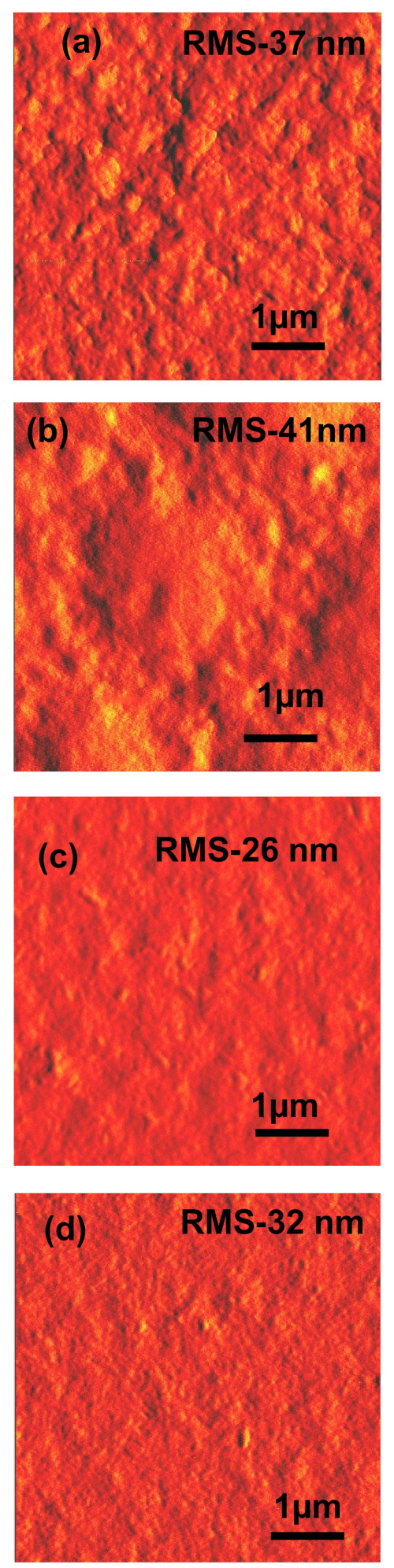

crystallization of P3HT in the blend, resulting in the presence of larger aggregates. Considering surface topography, octyl derivatives $\mathbf{3 b}-\mathbf{4 b}$ are expected to show better device performance than analogues 3a-4a due to more optimal facilitation of charges in the devices. Furthermore, despite the fact that the LUMO level of compound $\mathbf{4 b}$ is closer to that of P3HT than its bromo analogue $\mathbf{3 b}$, and compound $\mathbf{4 b}$ contributes more to the overall absorption of the blend, compound $\mathbf{3 b}$ exhibits a smoother surface, and thus should show higher efficiency.

The crystallinity and packing behavior of the P3HT: PDIglass blends in a 1:1 ratio were further studied by XRD. The XRD results for films of blends of P3HT with PDI glasses 3-4 after annealing at $110{ }^{\circ} \mathrm{C}$ for 10 minutes are shown in Figure 5. Diffractograms of the P3HT blends with all four PDI glasses are similar. One prominent diffraction peak was observed for all blends at angle $\left(2 \Theta=5-7^{\circ}\right)$ showing the first order structure of P3HT with a $d$ spacing of $1.7 \mathrm{~nm}$. The pristine films of P3HT: PDI blends exhibit weak signals as compared to annealed samples. The weak signals observed for pristine films are due to the low-order structure of P3HT. After annealing, the diffraction peak is increased in all fourblend films but more pronounced in films of P3HT with bromo derivatives 3a-b. Interestingly, in the blends with compound 3a-b, the P3HT crystalline peak was more intense than in the blend with pyrrolidinyl analogues $\mathbf{4 a - 4 b}$, hinting that compound $\mathbf{3 b}$, while remaining amorphous, promotes crystallization of P3HT in the blend. The slight increase of peak intensity for P3HT blends with $\mathbf{4 a - b}$ as compared to 3ab suggests little modification in the packing of PDI glass molecules upon improved phase separation. It is therefore suggested that the pyrolidinyl groups in compounds $4 \mathbf{a}-\mathbf{b}$ hinder the crystallization of P3HT.

The electron acceptor behavior of PDI glasses 3-4 was further studied by photoluminescence quenching, which is a characteristic behavior of acceptor materials in photovoltaic applications. $^{22} \quad$ Photoluminescence quenching for representative PDI glasses $\mathbf{3 a}$ and $\mathbf{3} \mathbf{b}$ were studied by the deposition of blends of compound 3a with highly luminescent polymer MDMO-PPV [Poly(2-methoxy-5-(3'7'dimethyloctyloxy)-1,4-phenylene-vinylene], and of compound $\mathbf{3 b}$ with P3HT. The photoluminescence (PL) 

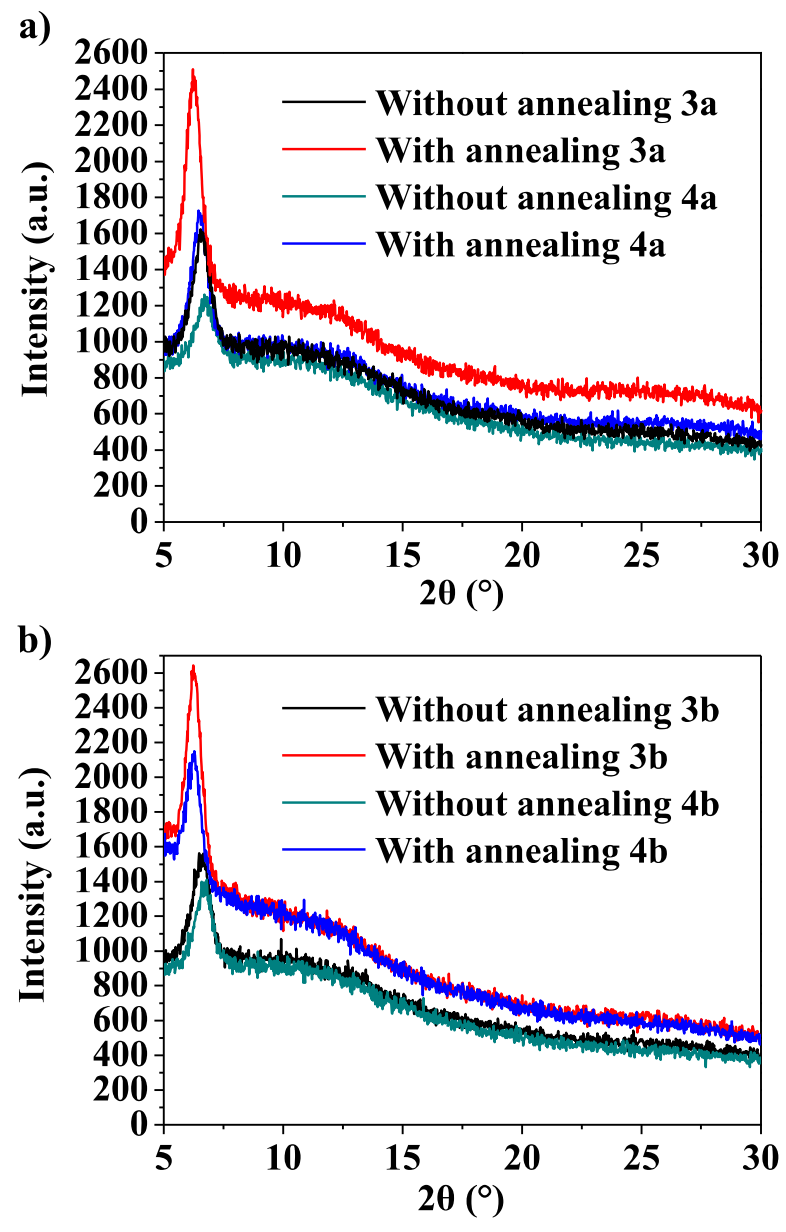

Figure 5. XRD for the blend films of P3HT with PDI derivatives (a) $\mathbf{3 a}$ and $\mathbf{4 a}$ (b) $\mathbf{3 b}$ and $\mathbf{4 b}$ spin-coated in dichlorobenzene solution. Films were annealed at $110^{\circ} \mathrm{C}$ for 10 minutes.

spectra of the blends were then recorded under a $360 \mathrm{~nm}$ LED excitation source. The PL spectra are depicted in Figure S6 (Supporting Information). The emission spectrum of pure MDMO-PPV shows a broad and intense band in the wavelength range 400-550 nm (Figure S6a), while P3HT shows a band in the range 600-750 nm (Figure S6b). As the concentration of PDI-glass is increased, the intensity of PL decreases for both polymers, and is totally quenched at PDIglass concentrations above $8 \mathrm{wt} \%$ for MDMO-PPV, while a 10 wt\% concentration of PDI-glass resulted in a twofold decrease in the PL intensity of P3HT. The quenching of polymer luminescence by PDI glasses $\mathbf{3 a}$ and $\mathbf{3 b}$ is attributed to electron transfer from the photo-excited donor polymer to the acceptor PDI molecules, as observed by Nikitenko et al in the study of photoluminescence quenching of MDMO-PPV by fullerene derivatives. ${ }^{48}$ The strong PL quenching by the PDI glasses suggests that in both cases, the two components exist as intimate blends constituted of small domains, rather than fully segregated biphasic structures.

\subsection{Device Fabrication and Performance}

Photovoltaic cells with inverted configurations were fabricated with blends of P3HT with PDI glasses 3-4 with P3HT: PDI-glass compositions of 1:2, 1:1 and 2:1 by mass. The blends were deposited by spin coating from dichlorobenzene solution on ITO substrates coated with 30 $\mathrm{nm}$ of ZnO. After annealing at $110^{\circ} \mathrm{C}$ for 10 minutes, which was determined to be the optimal annealing time, the active layers were then coated with a layer of $\mathrm{MoO}_{3}$ and an $\mathrm{Ag}$ electrode. Photovoltaic measurements were performed in ambient condition using light from a Xenon source calibrated with an AM 1.5 solar simulator to reproduce an incident light intensity of $100 \mathrm{mWcm}^{-2}$. The measurements were carried out at ambient atmosphere and the current-voltage curves for PDI glasses 3-4 are shown in Figure 6; characteristics in the dark are given for comparison in Figure S7. The power conversion efficiency (PCE) was calculated from the value of opencircuit voltage $\left(\mathrm{V}_{\mathrm{oc}}\right)$, short-circuit current density $\left(\mathrm{J}_{\mathrm{sc}}\right)$ and fill factor (FF) with the following equation: $\mathrm{PCE}=\mathrm{P}_{\text {out }} / \mathrm{P}_{\text {in }}=$ $J_{\mathrm{sc}} \times V_{\mathrm{oc}} \times F F / P_{\text {in }}$, where $P_{\text {in }}$ represents the power of incident light $\left(\mathrm{mW} / \mathrm{cm}^{2}\right)$. The fill factor was calculated from the values of $\mathrm{V}_{\mathrm{oc}}, \mathrm{J}_{\mathrm{sc}}$, and maximum power $\left(\mathrm{P}_{\max }\right)$ according to the following equation: $\mathrm{FF}=\mathrm{P}_{\max } / \mathrm{J}_{\mathrm{sc}} \times \mathrm{V}_{\mathrm{oc}}=\mathrm{J}_{\max } \times \mathrm{V}_{\max } / \mathrm{J}_{\mathrm{sc}} \times \mathrm{V}_{\mathrm{oc}}$, where $J_{\max }$ and $V_{\max }$ are the current density and voltage at maximum power respectively. The photovoltaic parameters of devices fabricated with PDI glasses 3-4 with varying donoracceptor ratios are reported in Table 5 (standard deviations are listed in Table S2).

Devices fabricated with bis(2,6-diisopropylphenyl) imide derivatives 3a-4a showed comparable efficiencies, which increased as the P3HT fraction increased, to reach maxima of $0.23 \%$ and $0.21 \%$ respectively for ratios of 2:1. Further increasing the P3HT:PDI glass ratio did not result in an improvement of the efficiency. $\mathrm{J}_{\mathrm{sc}}$ and $\mathrm{FF}$ values were also higher for devices built with glass $3 a$, while $V_{\text {oc }}$ was higher for glass 4a, possibly a consequence of the higher LUMO level of compound $\mathbf{4 a}$. This behavior is consistent with observations reported in the literature. ${ }^{14}$ On the other hand, devices fabricated with dioctylimide analogues $\mathbf{3 b}$ and $\mathbf{4 b}$ showed power conversion efficiencies three times higher, with maximal observed efficiencies of $0.66 \%$ and $0.63 \%$, respectively. Current density was also increased by values ranging from $66 \%$ to $150 \%$, while fill factors were increased by $16 \%$ to $19 \%$. Interestingly, for the octyl derivatives, higher efficiencies were observed with increasing the fraction of PDI relative to $\mathrm{P} 3 \mathrm{HT}$, which is a trend opposite to that observed for analogues 3a-4a. The imide groups obviously play an important role in the performance of the materials as electron acceptors. As suggested previously, while bulky 2,6diisopropylphenyl groups shield the perylene core from individual molecules, the linear octyl chains lead to more optimal $\pi-\pi$ stacking of the PDI moieties, thereby improving electron transfer between acceptor molecules. For both the 2,6-diisopropylphenyl and octyl series, efficiencies were comparable between bromo-substituted derivatives $\mathbf{3 a - b}$ and pyrrolidinyl derivatives $\mathbf{4 a - b}$. While pyrrolidinyl analogues 
a)
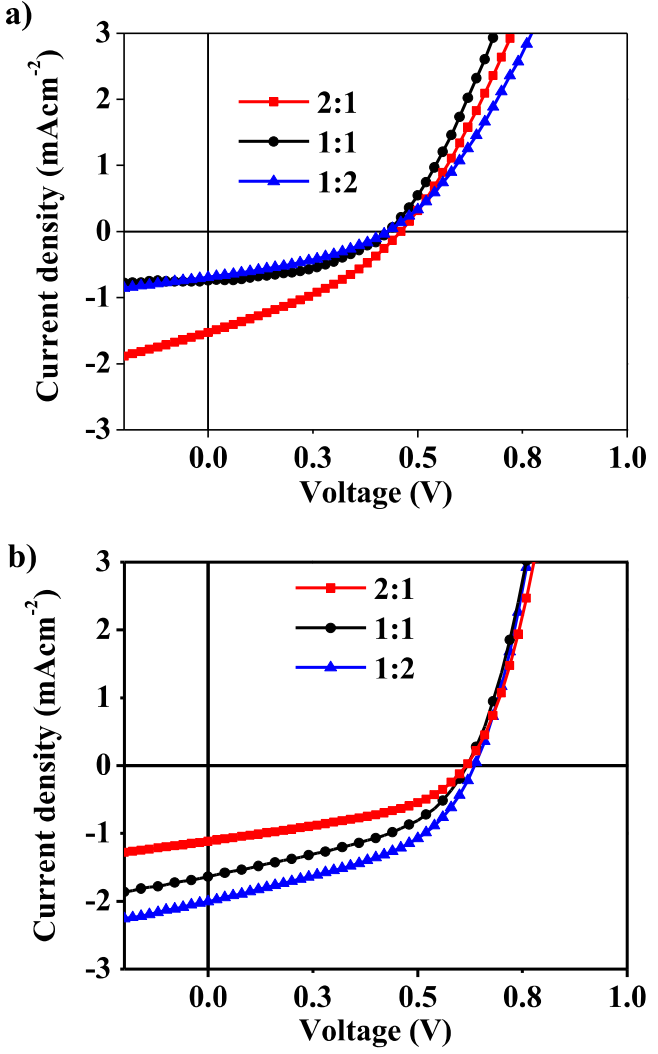

c)

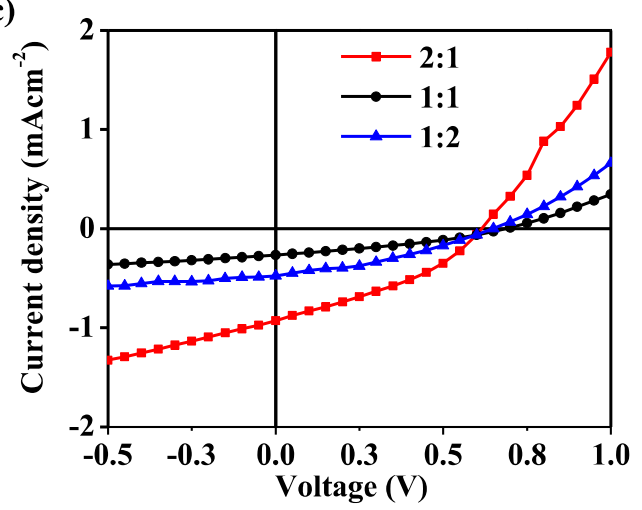

d)

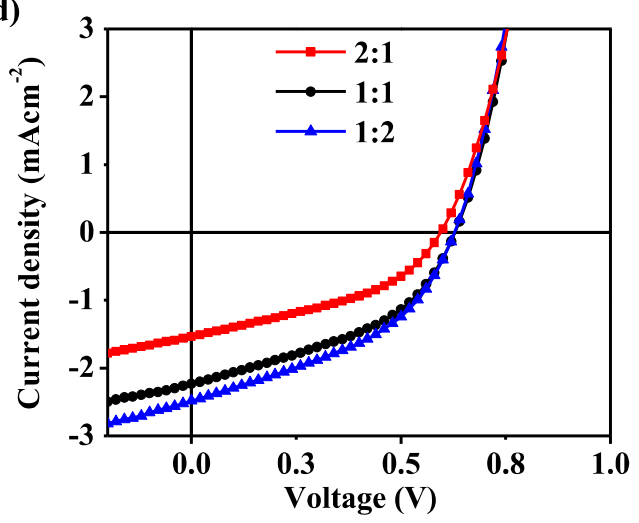

Figure 6. Current-voltage curves of ITO/ZnO/P3HT: PDIglass $/ \mathrm{MoO}_{3} / \mathrm{Ag}$ with PDI glass (a) 3a, (b) 3b, (c) 4a, and (d) 4b under illumination with an intensity of $100 \mathrm{~mW} \mathrm{~cm}^{-2}$. 4a-b better contributed to the overall absorption of the blends and possess LUMO levels closer to the LUMO level of P3HT, bromo derivatives 3a-b gave films with smoother topographies that are a result of smaller crystalline P3HT domains. Compound $\mathbf{3 b}$ also favored the crystallization of P3HT, as observed by XRD. The molecular properties of pyrrolidinyl derivatives $\mathbf{4 a - b}$ are counterbalanced by the superior supramolecular properties of bromo-substituted compounds 3a-b, leading to similar performances. Analysis of the current voltage characteristics reveals that incorporation of PDIs $\mathbf{3 b}$ and $\mathbf{4 b}$ into P3HT cells does not degrade the electrical characteristics of the blend; in particular, the series and shunt resistances that are given by the inverse of the slopes of the curves at zero and positive bias, respectively are independent of the molar fraction of PDI-glass. That is opposite to the situation with $\mathbf{3 a}$ and $\mathbf{4 a}$, which reveals that octyl-substituted PDIs do not add charge traps or recombination centers into the cells. ${ }^{49}$ Interestingly, the fact that the acceptor domains are completely amorphous within the devices does not prevent the molecules to pack in a way that allows electron transfer over long range, leading to photovoltaic efficiencies that are in the upper range of reported values for photovoltaic cells with P3HT and similar PDI derivatives. In comparison, reported efficiencies of PV cells with bis(3-pentyl) PDI and a 1,4,5,8-tetraalkyl analogue have yielded efficiencies of $0.25 \%$ and $0.5 \%$, respectively, ${ }^{10,41}$ while a PDI derivative with acenaphthenyl bay substituents gave a PCE of $0.96 \% .^{21}$ In fact, all reported instances of PDI derivatives giving significantly higher efficiencies with P3HT as donor contain two or more PDI moieties bridged by an aromatic linker, rather than a single PDI unit. ${ }^{50-53}$

Table 5. Photovoltaic parameters of ITO/ZnO/P3HT:PDIglass $/ \mathrm{MoO}_{3} / \mathrm{Ag}$ bulk-hetero junction devices with PDI glasses 3-4 under illumination with an intensity of $100 \mathrm{~mW} \mathrm{~cm}^{-2}$.

\begin{tabular}{llllll}
\hline $\begin{array}{l}\text { PDI } \\
\text { Glass }\end{array}$ & P3HT:PDI & $\begin{array}{l}\mathbf{J}_{\mathbf{s c}} \\
\left(\mathbf{m A c m} \mathbf{A c m}^{-2}\right)\end{array}$ & $\mathbf{V}_{\text {oc }}(\mathbf{V})$ & FF (\%) & $\begin{array}{l}\text { PCE } \\
\mathbf{( \% )}\end{array}$ \\
\hline 3a & $2: 1$ & 1.49 & 0.44 & 34.2 & 0.23 \\
\hline & $1: 1$ & 0.74 & 0.42 & 45.0 & 0.14 \\
\hline & $1: 2$ & 0.69 & 0.42 & 36.9 & 0.11 \\
\hline 3b & $2: 1$ & 1.53 & 0.60 & 40.7 & 0.37 \\
\hline & $1: 1$ & 2.23 & 0.62 & 43.3 & 0.60 \\
\hline & $1: 2$ & 2.48 & 0.62 & 43.0 & 0.66 \\
\hline 4a & $2: 1$ & 0.9 & 0.60 & 37 & 0.21 \\
\hline & $1: 1$ & 0.5 & 0.65 & 34 & 0.10 \\
\hline & $1: 2$ & 0.5 & 0.55 & 29 & 0.08 \\
\hline 4b & $2: 1$ & 1.24 & 0.64 & 44 & 0.34 \\
\hline & $1: 1$ & 2.00 & 0.64 & 43.4 & 0.55 \\
\hline & $1: 2$ & 2.33 & 0.64 & 42.6 & 0.63 \\
\hline
\end{tabular}




\section{Conclusions}

Four glass-forming perylenediimide derivatives containing mexylaminotriazine groups in the bay position were synthesized, characterized, and incorporated as electron acceptor materials in solution-processed organic photovoltaic cells with P3HT as a donor. It was found that while devices with all four materials showed photovoltaic behaviour, bulky groups at the imide position hindered the $\pi-\pi$ stacking necessary for electron transport. On the other hand, the bay substituents, used to tune the absorption in the visible range and the HOMO and LUMO levels, showed little impact on device performances. Even though the acceptor materials were completely amorphous in the devices, proper packing of the molecules allowing descent electron transport could be attained, leading to devices with power conversion efficiencies reaching $0.66 \%$, which are comparable to performances of other perylenediimide derivatives and P3HT and to earlier results using fullerene derivatives. Further optimization of the devices will be undertaken in the future and is expected to yield improved performance.

\section{Acknowledgements}

We acknowledge the Canadian Defence Academic Research Programme (CDARP) of RMC and the Discovery Grants Program of Natural Sciences and Engineering Research Council (NSERC) (NSERC \#327116) for supporting this research. We would also like to thank Dr. René Gagnon (Université de Sherbrooke) for mass spectroscopy analyses.

\section{Supporting Information}

DSC scans, cyclic voltammograms, additional device characterization data, and NMR spectra.

\section{Notes and references}

‡ Marvin was used for drawing, displaying and characterizing chemical structures, substructures and reactions, Marvin 15.1.12, 2015, ChemAxon (www.chemaxon.com).

1. F.C Krebs. Polymer Photovoltaics : A practical approach. SPE Press: Bellingham: Washington, USA, 2008; Vol. 1-4.

2. P. Kamat. Meeting the Clean Energy Demand: Nanostructure Architectures for Solar Energy Conversion. J. Phys. Chem C., 2007, 111, 2834-2860.

3. C. Li, and H. Wonneberger. Perylene Imides for Organic Photovoltaics: Yesterday, Today, and Tomorrow. Adv. Mater., 2012, 24, 613-636.

4. C.W. Tang. Two Layer Organic Photovoltaic Cell. Appl. Phys. Lett., 1986, 48, 183-185.

5. Y. Liu, J. Zhao, Z. Li, C. Mu, W. Ma, H. Hu, K. Jiang, H. Lin, H. Ade and H. Yan. Aggregation and morphology control enables multiple cases of high-efficiency polymer solar cells. Nat. Commun., 2014, 5, 5293. DOI: 10.1038/ncomms6293.

6. S.-H. Liao, H.-J. Jhuo, P.-N. Yeh, Y.-S. Cheng, Y.-L. Li, Y.-
H. Lee, S. Sharma and S.-A. Chen. Single Junction Inverted Polymer Solar Cell Reaching Power Conversion Efficiency 10.31\% by Employing Dual-Doped Zinc Oxide Nano-Film as Cathode Interlayer. Sci. Rep., 2014, 4, 6813. DOI:10.1038/srep06813

7. Z. He, C. Zhong, S. Su, M. Xu, H. Wu and Y. Cao. Enhanced power-conversion efficiency in polymer solar cells using an inverted device structure. Nat. Photonics, 2012, 6, 591-595;

8. L. Dou, J. You, Z. Hong, Z. Xu, G. Li, R.A. Street and Y. Yang. 25th Anniversary Article: A Decade of Organic/Polymeric Photovoltaic Research. Adv. Mater., 2013, 25, 6642-6671.

9. Z. Kişnişci, Ö.F. Yüksel and M. Kuş. Optical properties of perylene-monoimide (PMI) and perylene-diimide (PDI) organic semiconductor thin films. Synth. Metals, 2014, 194, 193-197;

10. V. Kamm, G. Battagliarin, I.A. Howard, W. Pisula, A. Mavrinskiy, C. Li, K. Müllen and F. Laquai. Polythiophene:Perylene Diimide Solar Cells - the Impact of Alkyl-Substitution on the Photovoltaic Performance. Adv. Energ. Mater., 2011, 1, 297-302.

11. D. Gendron and M. Leclerc. New conjugated polymers for plastic solar cells. Energy Environ. Sci., 2011, 4, 12251237.

12. J. Roncali, P. Leriche and P. Blanchard. Molecular Materials for Organic Photovoltaics: Small is Beautiful. Adv. Mater., 2014, 26, 3821-3838.

13. V. Malytskyi, J.-J. Simon, L. Patrone and J.-M. Raimundo. Thiophene-based push-pull chromophores for small molecule organic solar cells (SMOSCs). RSC Adv., 2015, 5, 354-397.

14. W.S. Shin, H.-H. Jeong, M.-K. Kim, S.-H. Jin, M.-R. Kim, J.-K. Lee, J.-W. Lee and Y.-S. Gal. Effects of functional groups at perylene diimide derivatives on organic photovoltaic device application. J. Mater. Chem., 2006, 16, 384-390.

15. Y. Lin and X. Zhan. Non-fullerene acceptors for organic photovoltaics: an emerging horizon. Mater. Horiz., 2014, 1, 470-488.

16. A.F. Eftaiha, J.-P. Sun, I.G. Hill and G.C. Welch. Recent advances of non-fullerene, small molecular acceptors for solution processed bulk heterojunction solar cells. J. Mater. Chem. A, 2014, 2, 1201-1213.

17. K. N. N. Unni, A. K. Pandey and J.-M. Nunzi. N-channel organic field-effect transistors using N,N' ditridecylperylene -3, 4, 9, 10 -tetracarboxylic diimide and a polymeric dielectric. Chem. Phys. Lett., 2005, 407, 95-99.

18. A.K. Pandey, K.N.N. Unni and J.-M. Nunzi. Pentacene / Perylene codeposited solar cells. Thin Solid Films, 2006, 511-512, 529-532.

19. J.C. Hummelen, B.W. Knight, F. LePeq, F. Wudl, J. Yao and C.L. Wilkins. Preparation and Characterization of Fulleroid and Methanofullerene Derivatives. J. Org. Chem., 1995, 60, 532-538.

20. Y. Lin, Y. Wang, J. Wang, J. Hou, Y. Li, D. Zhu and X. Zhan. An Electron Acceptor Challenging Fullerenes for Efficient Polymer Solar Cells. Adv. Mater., 2014, 26, 51375142.

21. E. Kozma, D. Kotowski, S. Luzzati, M. Catellani, F. Bertini, A. Famulari and G. Raos. Improving the efficiency of P3HT:perylene diimide solar cells via bay-substitution with fused aromatic rings. RSC Adv., 2013, 3, 9185-9188.

22. E. Kozma and M. Catellani. Perylene diimides based materials for organic solar cells. Dyes Pigm., 2013, 98, 160179.

23. C.A. Angell. Formation of Glasses from Liquids and 
Biopolymers. Science, 1995, 267, 1924-1935.

24. M.D. Ediger, C.A. Angell and S.R. Nagel. Supercooled Liquids and Glasses. J. Phys. Chem., 1996, 100, 1320013212.

25. L. Duan, L. Hou, T.-W. Lee, J. Qiao, D. Zhang, G. Dong, L. Wang and Y. Qiu. Solution processable small molecules for organic light-emitting diodes. J. Mater. Chem., 2010, 20, 6392-6407.

26. V. Sivamurugan, R. Lygaitis, J.V. Grazulevicius, V. Gaidelis, V. Jankauskas and S. Valiyaveettil. Effect of substituents on the electron transport properties of bay substituted perylene diimide derivatives. J. Mater. Chem., 2009, 19, 4268-4275.

27. V. Sivamurugan, K. Kazlauskas, S. Jursenas, A. Gruodis, J. Simokaitiene, J.V. Grazulevicius and S. Valiyaveettil. Synthesis and Photophysical Properties of Glass-Forming Bay-Substituted Perylenediimide Derivatives. J. Phys. Chem. B, 2010, 114, 1782-1789.

28. P. Strohriegl and J.V. Grazulevicius. Charge-Transporting Molecular Glasses. Adv. Mater., 2002, 14, 1439-1452.

29. Y. Shirota, and H. Kageyama. Charge Carrier Transporting Molecular Materials and Their Applications in Devices. Chem. Rev., 2007, 107, 953-1010.

30. R. Lygaitis, V. Getautis and J.V. Grazulevicius. Holetransporting hydrazones. Chem. Soc. Rev., 2008, 37, 770788.

31. Y. Shirota. Organic materials for electronic and optoelectronic devices. J. Mater. Chem., 2000, 10, 1-25.

32. J. Nakano, T. Takahashi, T. Kadota and Y. Shirota. Formation of a Surface Relief Grating Using a Novel Azobenzene-Based Photochromic Amorphous Molecular Material. Adv. Mater., 2002, 14, 1157-1160.

33. E. Ishow, B. Lebon, Y. He, X. Wang, L. Bouteiller, L. Galmiche and K. Nakatani. Structural and Photoisomerization Cross Studies of Polar Photochromic Monomeric Glasses Forming Surface Relief Gratings. Chem. Mater., 2006, 18, 1261-1267.

34. D. Nagahama, H. Nakano and Y. Shirota. Synthesis and Photochromic Response of a New Photochromic Amorphous Molecular Material Based on Spirooxazine. Photopolym. Sci. Technol., 2008, 21, 755-757.

35. K. Traskovskis, I. Mihailovs, A. Tokmakovs, A. Jurgis, V. Kokars and M. Rutkis. Triphenyl moieties as building blocks for obtaining molecular glasses with nonlinear optical activity. J. Mater. Chem., 2012, 22, 11268-11276.

36. J.D. Wuest and O. Lebel. Anarchy in the solid state: structural dependence on glass-forming ability in triazinebased molecular glasses. Tetrahedron, 2009, 65, 7393-7402.

37. R.N. Eren, A. Plante, A. Meunier, A. Laventure, Y. Huang, J.G. Briard, K.J. Creber, C. Pellerin, A. Soldera and O. Lebel. One ring to rule them all: effect of aryl substitution on glass-forming ability in mexylaminotriazine molecular glasses. Tetrahedron, 2012, 68, 10130-10144.

38. A. Laventure, A. Soldera, C. Pellerin and O. Lebel. Heads vs. tails: a double-sided study of the influence of substituents on the glass-forming ability and stability of aminotriazine molecular glasses. New J. Chem., 2013, 37, 3881-3889.

39. R. Kirby, R.G. Sabat, J.-M. Nunzi and O. Lebel. Disperse and disordered: a mexylaminotriazine-substituted azobenzene derivative with superior glass and surface relief grating formation. J. Mater. Chem. C, 2014, 2, 841-847.

40. O.R. Bennani, T.A. Al-Hujran, J.-M. Nunzi, R.G. Sabat and O. Lebel. Surface relief grating growth in thin films of mexylaminotriazine-functionalized glass-forming azobenzene derivatives. New J. Chem., 2015, 39, 91629170.
41. X. Guo, L. Bu, Y. Zhao, Z. Xie, Y. Geng and L. Wang. Controlled phase separation for efficient energy conversion in dye/polymer blend bulk heterojunction photovoltaic cells. Thin Solid Films, 2009, 517, 4654-4657.

42. R. Singh, E. Giussani, M.M. Mróz, F. Di Fonzo, D. Fazzi, J. Cabanillas-González, L. Oldridge, N. Vaenas, A.G. Kontos, P. Falaras, A.C. Grimsdale, J. Jacob, K. Müllen and P.E. Keivanidis. On the role of aggregation effects in the performance of perylene-diimide based solar cells. Org. Electron., 2014, 15, 1347-1361.

43. H. Dinçalp, Ş. Kızılok and S. İçli. Fluorescent macromolecular perylene diimides containing pyrene or indole units in bay positions. Dyes Pigm., 2010, 86, 32-41.

44. M.J. Ahrens, M.J. Tauber and M.R. Wasielewski. Bis(noctylamino)perylene-3,4:9,10-bis(dicarboximide)s and Their Radical Cations: Synthesis, Electrochemistry, and ENDOR Spectroscopy. J. Org. Chem., 2006, 71, 21072114.

45. B. Gholamkhass, N.M. Kiasari and P. Servati. An efficient inverted organic solar cell with improved $\mathrm{ZnO}$ and gold contact layers. Org. Electron., 2012, 13, 945-953.

46. D. Pathak, T. Wagner, T. Adhikari and J.-M. Nunzi. Photovoltaic performance of AgInSe 2 -conjugated polymer hybrid system bulk heterojunction solar cells. Synth. Metals, 2015, 199, 87-92.

47. M. Queste, C. Cadiou, B. Pagoaga, L. Giraudet and N. Hoffmann. Synthesis and characterization of 1,7disubstituted and 1,6,7,12-tetrasubstituted : derivatives. New J. Chem., 2010, 34, 2537-2545.

48. S. Nikitenko, J. Mayorova, P. Troshin, R. Lyubovskaya and M. Kaplunov. Photoluminescence Quenching Study of Composites Comprising Novel Fullerene-Based Acceptors and MDMO-PPV. Mol. Cryst. Liq. Cryst., 2007, 468, 239/ [591]-244/[596].

49. A. Moliton and J.-M. Nunzi. How to model the behaviour of organic photovoltaic cells. Polym. Internat., 2006, 55, 583-600.

50. Z. Lu, X. Zhang, C. Zhan, B. Jiang, X. Zhang, L. Chen and J. Yao. Impact of molecular solvophobicity vs. Solvophilicity on device performances of dimeric perylene diimide based solution-processed non-fullerene organic solar cells. Phys. Chem. Chem. Phys., 2013, 15, 1137511385.

51. B. Jiang, X. Zhang, C. Zhan, Z. Lu, J. Huang, X. Ding, S. He and J. Yao. Benzodithiophene bridged dimeric perylene diimide amphiphiles as efficient solution-processed nonfullerene small molecules. Polym. Chem., 2013, 4, 46314638.

52. Q. Yan, Y. Zhou, Y. Zheng, J. Pei and D. Zhao. Towards rational design of organic electron acceptors for photovoltaics: a study based on perylenediimide derivatives. Chem. Sci., 2013, 4, 4389-4394.

53. J. Lee, R. Singh, D.H. Sin, H.G. Kim, K.C. Song and K. Cho. A Nonfullerene Small Molecule Acceptor with 3D Interlocking Geometry Enabling Efficient Organic Solar Cells. Adv. Mater., 2015, 27, DOI: 10.1002/adma.201504010. 